have a most deleterious effect on the health of children. I think, therefore, it is not unreasonable that the school doctor should consider the whole environment of the school and not be concerned with developmental assessment isolated from some of the factors which could affect overall development.

I think it is not usual for the examination of teachers to be part of the duties of a school medical officer. Most authorities tend to have separate sessions at which medical officers may be asked to undertake such examinations and, again, I do not feel that they can be completely divorced from concern for the health and welfare of the child. There can be few more harmful influences on a child's career than to be subjected to a physically or mentally disturbed teacher. Again I speak from personal experience and I think it is sound that doctors who work in the school health service should have some opportunity of considering the suitability of teachers, on medical grounds, to work with children.

Finally, it has long been considered a duty of all doctors in the preventive field to practise health education, and why this should be considered wrong for school doctors is completely beyond my comprehension. I would have hoped that both $\mathrm{Dr}$. Bamford and Professor Davis practised health education diligently during their work as paediatricians.

I would not wish my criticism of one section of the paper to imply any other than general agreement with the views of the authors and respect for their excellent paper. -I am, etc.,

ANTONY J. Essex-CATER Monmouthshire County Health Department, Newport, Mon

\section{Occupational Medicine?}

SIR,-Your leading article (3 February, p. 250) expresses criticisms of the Robens Report that will find a wide measure of agreement among doctors working in industry. However, the statement that "occupational physicians and occupational health nurses spend up to $90 \%$ of their time in aiding the resettlement and rehabilitation of people who have been or are becoming sick or disabled and need a change in their work" does appear to exaggerate the extent of this particular function.

It is true that the doctor or nurse within a works has the advantage over colleagues outside industry of knowledge of the demands of various types of work, and experience of the effects of these upon persons in varying states of health. But this advantage is of value in other aspects of occupational medicine. When new materials are introduced the first indication of toxic reactions may be the occurrence of minor sickness seen at the works clinic, and such an observation may lead to immediate investigation and elimination of a potential risk before serious harm occurs. A medical service based outside the works must wait for official reports of one sort or another before any problem is known to exist. The introduction of new materials is unceasing, so that detection, investigation, and elimination of new hazards is an increasingly important function of the works medical officer.

The Robens Committee implied that the works doctor wastes medical resources by duplicating functions of the N.H.S. Yet the works clinic acts as an observation post for what is going on not only in the works, but also at all levels of management, where the causes of stress may be detected sooner and morc effectively by the man on the spot than by observers based outside the works. It is an oversimplification to regard rehabilitation and resettlement as the major part of his work. Nevertheless you are right in saying that we have failed signally to be sufficiently explicit and convincing abou what occupational medicine is. $-I$ am, etc.

\section{W. K. S. MOORE}

Occupational Health Service,

The Boots Company Ltd.

Nottingham

SIR,-In your recent leading article "Occupa-
tional Medicine?" (3 February, p. 250) (the question mark is significant) you suggest that a concept of occupational medicine wider than that shown by the Robens Committee is needed.

The practice of occupational medicine is the application of medical art and science to people in their working situation, to help them keep and improve health. This concept is sufficiently wide to embrace all those matters with which, as you point out, many occupational physicians and nurses have for long been concerned. Interest in occupational medicine is quickening, not only in the medical schools but also among the general public, and if those who know its importance exert their influence, as they may be expected to do, occupational medicine will soon be accepted as part of medicine as a whole and its isolation from the mainstream of medical life ended.-I am, etc.,

University of Bristol

T. G. F. HUdSON

\section{Children's Wheelchairs}

SIR,-In reply to Dr. R. H. Taylor's letter (20 January, p. 173) concerning children's wheelchairs, the equipment is traditional not only because the engineers who design it do not have correct training but also because those who prescribe it do not give the correct details. It is not for the engineers to prescribe.

There are few anthropometric data on normal children under the age of five and none on handicapped children. The clinical involvement of engineers is, as Dr. Taylor states, non-existent. Equally, there is no move in the medical, nursing, and paramedical professions to include modern technology in their trainings-that is, anatomy in relation to biomechanics and anthropometrics, physiology in relation to work, and environmental physiology and psychology in relation to skill and occupational psychology. These are the components of ergonomics. Poor ergonomics can exist only when ergonomic principles are applied.

Ergonomics is a technical subject which is concerned with the careful collection of data about individuals as physiological and psychological beings in an endeavour to make the physical working environment compatible with them. It is used by industry in car design and in the armed Forces, but rarely in the National Health Service. It is time that it became a subject of serious postgraduate study for relevant sections of the health service.

If the design of equipment and aids, not only for children, but for handicapped and impaired people in general, is to be improved, then those who prescribe them must be correctly trained. Do not let us condemn the engineers and designers who are doing their best to provide equipment when they are not given the correct specification because of lack of training of the prescriber. Let the blame be fairly taken.

I am a nurse and an ergonomist but was unable to find any post in the Health Service where I could use my ergonomic training. Fortunately for me, industry is not so backward.-I am, etc.,

Pauline Bretten

London E.18

\section{Sponsored Hospitality}

SIR,-Mr. K. Norcross in his letter (3 February, p. 294) concerning drug firm hospitality raises what appears to him to be a disquieting point.

As a junior doctor I have attended many such meetings in a number of hospitals in this region and I can see how distasteful such hospitality can appear to be if it is misunderstood by those not attending the meeting. This hospitality certainly provides the likes of me with some light relief, but I feel that the lure of some food or drink only increases the enjoyment of the meeting and the numbers attending. I do not feel any more favourably disposed to the drug firm's products. Indeed, the atmosphere merely favours a more lively, critical, and often amusing discussion.

I think it is a shame that these meetings should be viewed with such suspicion and even banned in some hospitals. We should surely not admit that we could be bribed into using one product rather than another, and the banning of such meetings does just that.-I am, etc.

STEPHEN BRENNAN

Royal Hospital,

Sheffeld

\section{Insulin Syringes}

SIR,-There has long been concern over mistakes which are made, particularlv by patients but also by nursing and medical staff, in the dosage of insulin. This is due in large measure to the various strengths per $\mathrm{ml}$ available on the market. Some effort to minimize these mistakes has been made by attempting to insist that only the B.S. 1619 insulin syringe should be used. Even this allows of mistake because of the use of terms like "single" and "double" strength. This can be confusing with soluble insulin, which is still supplied in strengths of 20,40 , and 80 units $/ \mathrm{ml}$.

In the U.S.A. it is proposed that only a single strength insulin of 100 units $/ \mathrm{ml}$ shall be on the market. I do not think this is suitable, as the greater the "strength" of the insulin, the greater the difficulty of measuring small doses or small dose changes. 